\title{
Efficiency of an AC Conductive In-Road Charging System for Electric Vehicles-Analysis of Pilot Project Data
}

\section{Mikael Hellgren and Nicholas Honeth ${ }^{\boldsymbol{1}}$}

${ }^{\prime}$ KTH Royal Institute of Technology, Sweden

\section{Abstract}

This article describes the conductive in-road charging system as developed in the eRoadArlanda project, a pilot project for the development of in-road charging system for both heavy and light vehicles intended for application in motorways. The results of an analysis of measurements collected during the integration tests of this system are presented and discussed. The results focus on the end-to-end efficiency of the in-road charging system and aim to provide researchers in the field with a reference for this technology and configuration for use in the future development of such infrastructure. The analysis of the measurement data addresses losses in the low-voltage side of the $\mathrm{AC}$ conductive charging system as well as the vehicle-mounted isolated rectifier/converter connected to the vehicle DC system. An exploratory analysis of data collected over a 6 -month testing period in varying weather conditions is used to provide insight into factors affecting the overall efficiency of the system. A discussion of the results includes the effects of cable dimensioning, rectifier performance and placement, and the use of salt for deicing. (c) 2020 Mikael Hellgren, Nicholas Honeth. Published by SAE International. This Open Access article is published under the terms of the Creative Commons Attribution License (http://creativecommons.org/licenses/by/4.0/), which permits distribution, and reproduction in any medium, provided that the original author(s) and the source are credited.

\section{History}

Received: 28 Jun 2019 Revised: 19 Nov 2019

Accepted: 04 Feb 2020 e-Available: 27 Feb 2020

\section{Keywords}

Electric road systems, Electric vehicles, Dynamic charging, Efficiency, Conductive charging

\section{Citation}

Hellgren, M., and Honeth, N., "Efficiency of an AC Conductive In-Road Charging System for Electric Vehicles-Analysis of Pilot Project Data," SAE Int. J. Elect. Veh. 9(1):27-40, 2020, doi:10.4271/14-09-01-0003.

ISSN: 2691-3747

e-ISSN: 2691-3755

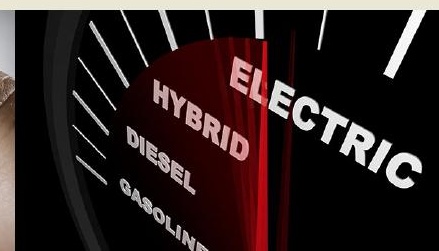




\section{Introduction}

lectric road systems (ERS) have become a research and development area of much interest during the past five years. The reason is that electric vehicle researchers and manufacturers are facing fundamental challenges, in that current battery technology and even the most promising battery technology of the near future does not scale well for heavy vehicles in addition to the material requirements if all passenger cars in the world would be electrified. Large-scale use of electric vehicle batteries has resource constraints in terms of material requirements; for example, cobalt and nickel are required in large volumes. Effective recycling of batteries that have passed their service life is also problematic $[1,2]$. ERS, which enable charging while driving along an electric road, could help to keep battery capacity requirements down compared to which battery electric vehicles (BEV) without ERS would require.

It is fully possible to feed a truck with more than the mean power required for long-haul vehicles. The ability to supply power for the drivetrain and for charging means that the vehicle battery size requirement decreases to the amount needed for travel back and forth to the electric road. If, for example, a truck is using $1 \mathrm{kWh} / \mathrm{km}$ (delivery truck) and the last-mile travel distance without electric roads is $2 \times 30 \mathrm{~km}$ then the required battery capacity would be $60 \mathrm{kWh}$ in addition to a base amount of around $10 \mathrm{kWh}$ for not depleting the battery under a certain level. The above mentioned is valid in terms of energy usage. The maximum power required for this kind of delivery truck in this size (18-ton total weight) is around $250 \mathrm{~kW}$. The discharge rate with a battery of $70 \mathrm{kWh}$ size will then be $\frac{250}{70} \approx 3.6 \mathrm{C}$. This is an acceptable discharge rate depending on the battery technology used. Commercial

BEV batteries in this size are readily available; however, should the truck be required to carry batteries with the capacity to cover a long-distance route the required battery would quickly become unreasonably large. According to []ㅡ, using the stateof-the-art battery technology in 2017, the battery weight for a long-haul truck that should have $1000 \mathrm{~km}$ range would be around 16 metric tons. A battery of this weight would take a considerable part of the load capacity for the truck. For this type of vehicle, the usage of electric roads could be even more suitable than for delivery trucks.

This paper aims to answer two questions, namely, where the main losses could be found in a conductive ERS and in particular the Elways solution and second, what the individual contributions of the inbound components of the system are to the total end-to-end efficiency.

\section{Background}

Today there are many different solutions for ERS, the main categories being conductive and inductive charging. Table 1
TABLE 1 Different technologies for ERS with values taken from the specified sources.

\begin{tabular}{|c|c|c|c|}
\hline $\begin{array}{l}\text { Type and } \\
\text { placement }\end{array}$ & Developer & $\begin{array}{l}\text { Length of demo } \\
\text { track }\end{array}$ & Source \\
\hline \multicolumn{4}{|l|}{ Conductive } \\
\hline In road & Elways & $2 \mathrm{~km}$ & {$[4]$} \\
\hline In road & $\begin{array}{l}\text { Alstom's APS } \\
\text { system }\end{array}$ & $\begin{array}{l}\text { Vehicle } 400 \mathrm{~m} \\
\text { (tram many } \mathrm{km} \text { ) }\end{array}$ & {$[\underline{5}]$} \\
\hline On road & Elonroad & $200 \mathrm{~m}$ & {$[\underline{6}]$} \\
\hline Beside road & Honda & $300 \mathrm{~m}$ & [7] \\
\hline Overhead lines & Siemens & $2 \mathrm{~km}$ & [] \\
\hline \multicolumn{4}{|l|}{ Inductive } \\
\hline & Bombardier & $80 \mathrm{~m}$ & [9] \\
\hline & Olev (KAIST) & $144 \mathrm{~m}$ & {$[10]$} \\
\hline & Qualcomm & $100 \mathrm{~m}$ & [11] \\
\hline & Wave & Approx. $100 \mathrm{~m}$ & {$[12]$} \\
\hline & $\begin{array}{l}\text { Electreon } \\
\text { (former } \\
\text { Electroad) }\end{array}$ & $25 \mathrm{~m}$ & [13] \\
\hline
\end{tabular}

shows an overview of ERS technologies under development and the known length of current demonstrator track facilities.

What follows is a short description of the different conductive technologies for reference. Inductive ERS technologies are not covered here.

The Elways conductive technology uses a rail sunk into the road surface. The rail is an E-shaped profile that is flush with the road surface. A conductive two-pole pickup on the vehicle guided into the slots of the track and makes an electric connection with the lower part of the E-profile. Rail sections are energized as the vehicle passes and disconnected from supply afterwards. The Elways technology will be discussed further in this article as the measurements and analysis were done on this system.

The Alstom' system shown in Figure 1 is similar to the Elways system in that it is built upon two electrified lines running in the road, but instead they are on the top of the electrified road. A pickup is pressed downwards to the lines for the conductive connection. This system was originally developed for tram systems, in which the line sections are only electrified under the tram for safety reasons. The system has been tested for truck usage on a shorter test track.

The Elonroad ERS uses a rail mounted on top of the road surface as shown in Figures 2 and $\underline{3}$. A pickup under the vehicle is lowered to the rail for the conductive connection. In a similar method to the other solutions, rail sections are powered on just under and in front of the vehicle for safety reasons.

Apart from these abovementioned systems, there is another system from Honda where a two-pole conductive rail is located on the side of the road from a fence, see Figure 4. The Honda system has been tested up to approximately 150 $\mathrm{km} / \mathrm{h}$ speed.

Finally, a system using overhead catenary lines is under development and evaluation. Conductive supply to vehicles using overhead lines is well-established in the technologies 


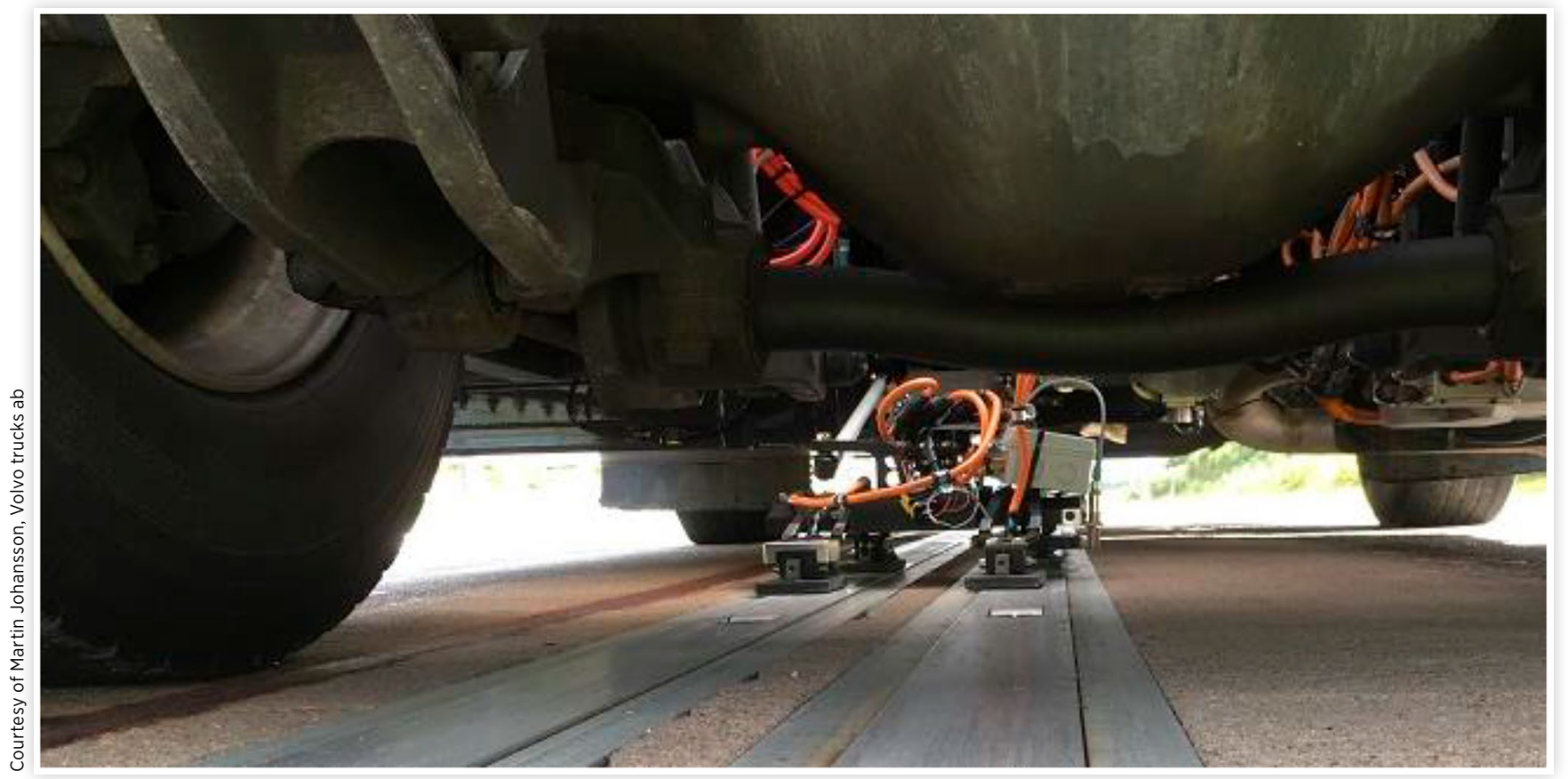

used in trolley bus systems [16]. In the ERS context, the Siemens overhead conductive system takes the power from two lines above the vehicle. This system is designed for vehicles with sufficient height compared to the lines, for example, trucks and buses but not light automobiles.

\section{Scope and Limitations}

The analysis presented here aims to quantify and discuss the end-to-end efficiency of the in-road conductive charging system. The data used for the analysis was gathered during the integration test phase of the project in the fall of 2018 and subsequent pilot operation during the spring of 2019.

The analysis does not include the transformer connected to the regional power grid. Most electrical utilities have specific requirements on this equipment and the characteristics of the equipment are well-known.

The technology discussed in this article is intended for application in a wide range of electric vehicles. In order to retain the general applicability of the results the vehicle drivetrain, therefore, is not considered. For a current review of electric vehicle drivetrain efficiency see [17]. Also, [18] considers electric drivetrains specifically for heavy road vehicles.

\section{The System under Test}

The in-road conductive charging system developed as part of the eRoadArlanda has its origins in the Elways [4] technology

\section{FIGURE 2 Rail and pickup from the side of the car, green light shows that electricity is engaged.}

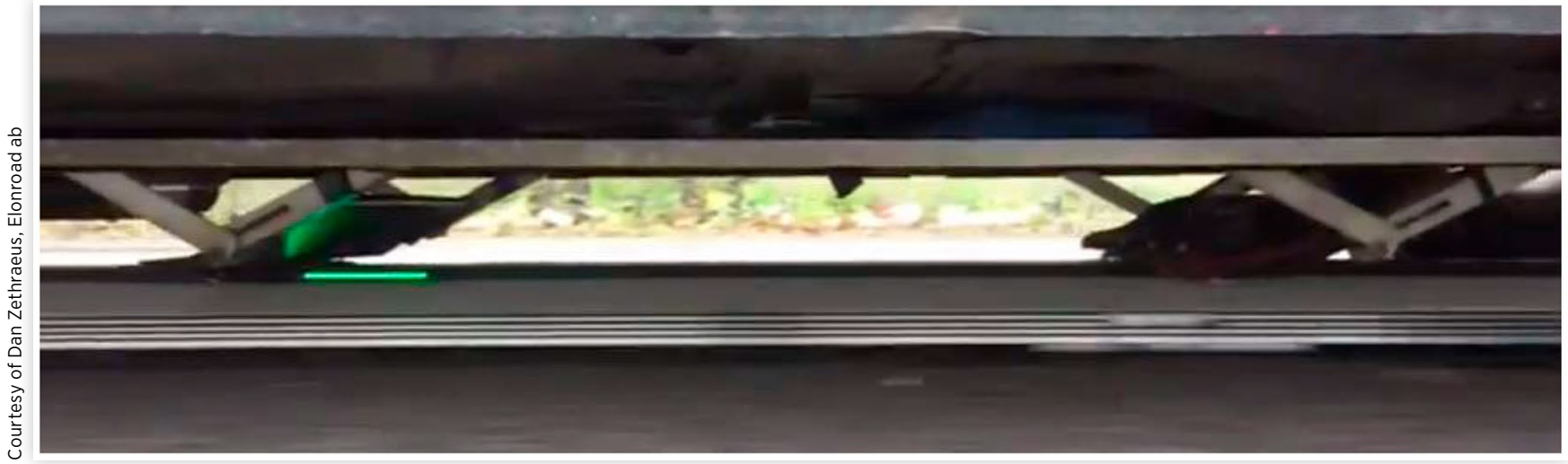


FIGURE 3 Rail on top of the road.

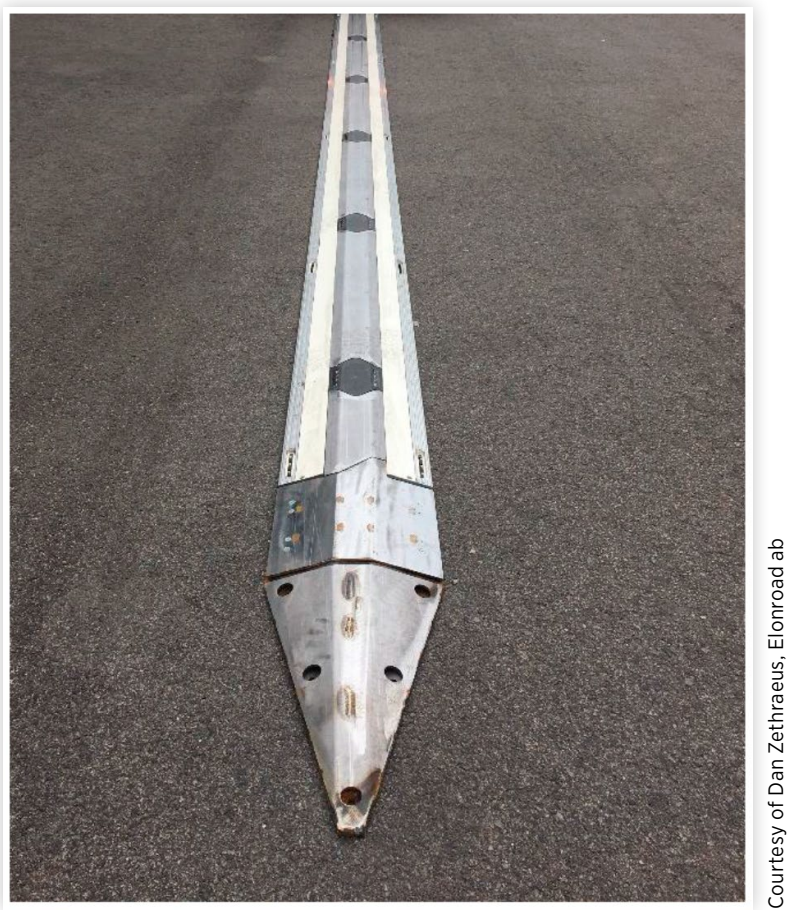

illustrated in Figure 5. The eRoadArlanda project is a consortium including an infrastructure contractor, transport and logistics operator, postal service, electric distribution utility, and a vehicle inspection company and electric drivetrain specialist. Additionally, there are two research institutes affiliated with the project. The project was financed as an innovation public acquisition by the Swedish Transport Administration, Swedish Energy Agency, and Vinnova.

Since the autumn of 2015 , the project has been in various testing phases with the first phase on a closed track. The second phase of testing on an open public road has been

FIGURE 4 Honda charging system with the side-mounted pickup [15].

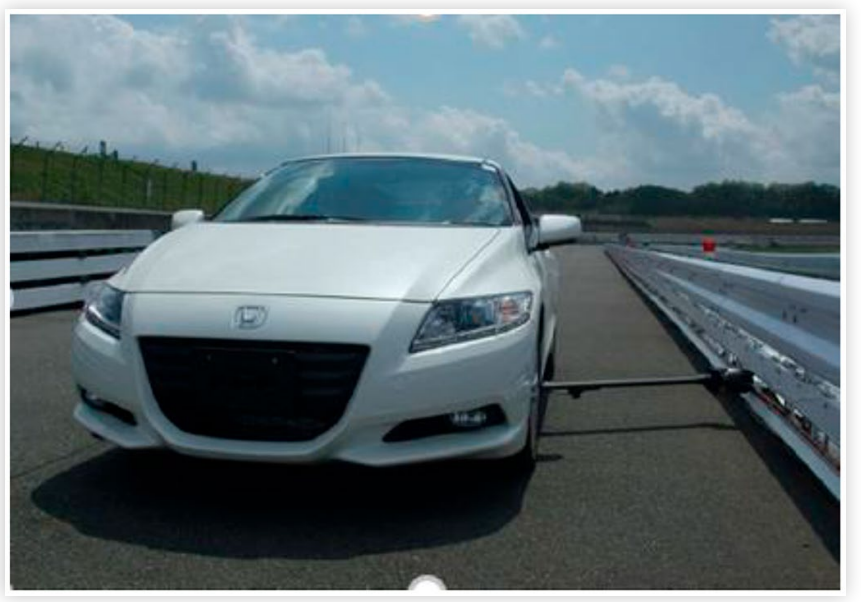

FIGURE 5 Conceptual illustration of eRoadArlanda conductive charging system.

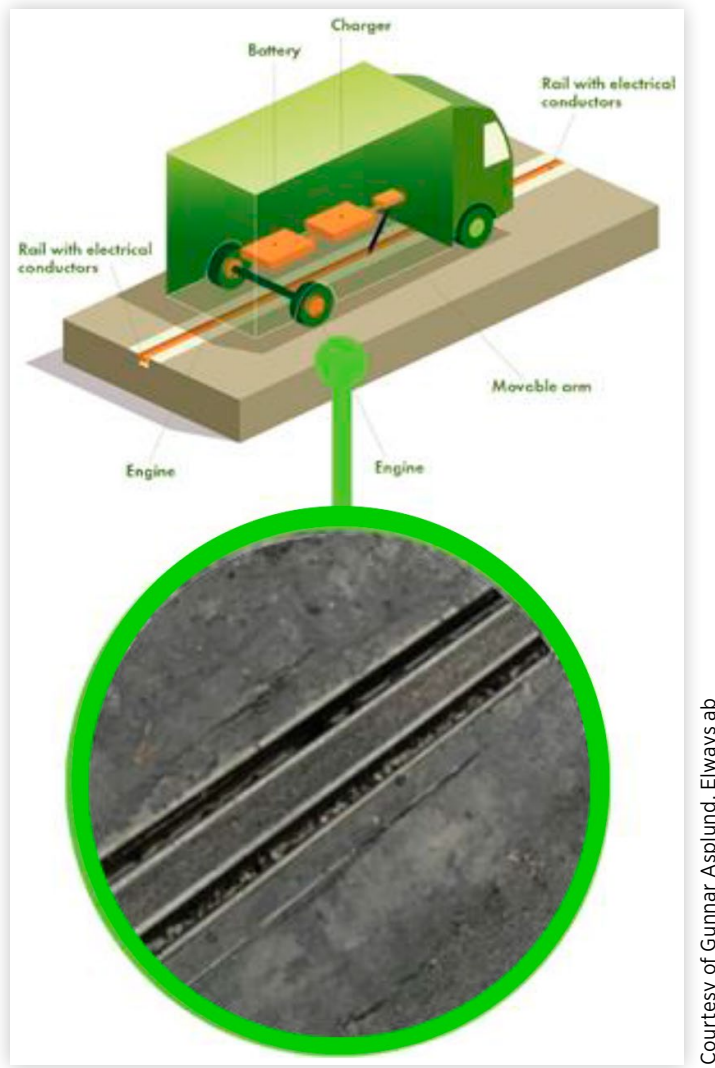

running since spring 2018 with a final round of integration tests performed during the autumn of 2018 before the project was authorized to commence commercial operation.

The cross section of construction of the conductive rail for the in-road charging concept is shown in Figure 6. The two conducting rails are embedded in an insulating layer inside an E-shaped profile.

Figure 7 shows the in-road rail-charging concept, which divides the conductive rail into $50 \mathrm{~m}$ sections that are individually energized as the vehicle enters the section and disconnected once the vehicle has moved to the next rail section. The electric vehicle used is equipped with a conductive pick-up arm, which actively tracks and connects to the rail. The vehicle is equipped with an onboard rectifier unit to convert the 800 VAC to ca. 630 VDC used by the battery.

The road system is able to deliver $250 \mathrm{~A}$ and 800 VAC. The voltage is floating relative to the protective earth. This means that a connection from one of the conductors to ground will not give any losses. If both conductors connect to ground there will be a current flowing from one conductor to the other via ground, a phase-to-phase leakage current. One reason for this leakage across the ground could be salt together with water, dust, and other materials that can collect in the rail. Salt is used for deicing in colder climates.

The present version of the Elways ERS uses AC power in the rail; there is however no fundamental hinder to using DC 
FIGURE 6 Cross section of the conductive rail system.

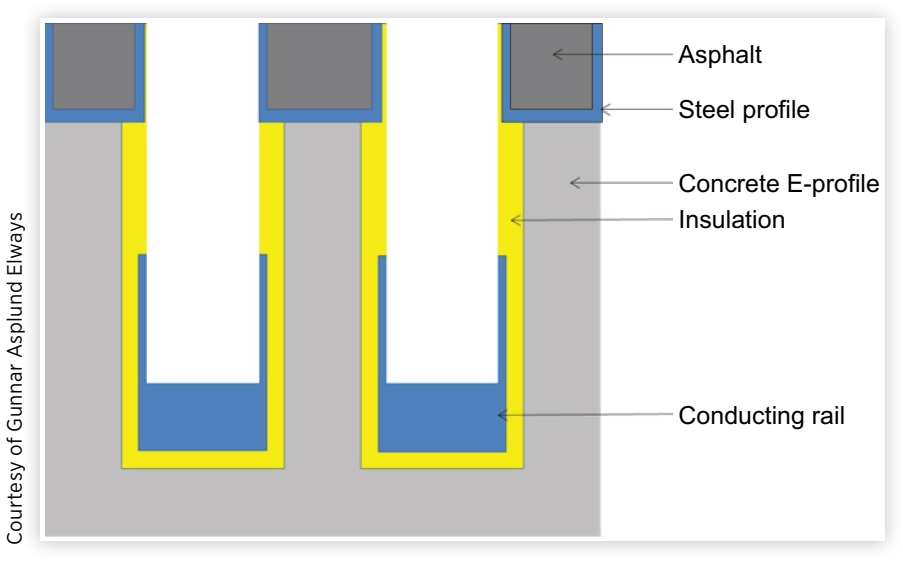

power in the concept as will be discussed later. The reason for having chosen $\mathrm{AC}$ is rather that all components required on the roadside were readily available from industrial suppliers.

When using AC power, an onboard rectifier has to be installed into the vehicle, while using DC power, a rectifier has to be installed near each transformer. A roadside rectifier should be able to supply all the vehicles connected at the same time to the transformer. The rectifier mounted in the vehicle only needs to feed that vehicle. The Elways ERS technology is designed for charging power ratings from 25 to $250 \mathrm{~kW}$, and the in-vehicle rectifier would need to be suitably dimensioned depending on the vehicle size.

For the eRoadArlanda demonstrator project, the choice of rectifier unit was influenced by safety requirements for a double-insulated galvanic separation between the AC and DC terminals. The rectifier, therefore, is a multistage converter including an input rectifier, capacitor, and a chopper that feeds a high-frequency transformer connected to a secondary highfrequency rectifier. A final regulator stage allows the battery charge power set point to be configured by the vehicle control system. Thermal losses are dissipated in a liquid-cooled system.

\section{Method and Data Collection}

The analysis is performed on data collected during a test period as well as measurements gathered during various phases of the eRoadArlanda demonstrator project.

Starting with a series of integration tests in 2018 and subsequent commercial operation, data has been collected from various loggers and measurement equipment integrated into both the eRoad and the vehicle.

Figure 8 shows the vehicle data collection system, which comprises an AC power analyzer, vehicle control system logger, and cameras for road and pick-up video recording.

Examples of data collected are AC voltage, current, phase angle at both the roadside contactor cabinets, and the $\mathrm{AC}$ input to the vehicle rectifier. Switching events in the roadside contactor cabinets are recorded at strategic points for assessment of the switching sequence and validation of safety functionality.

Additional logging of both the vehicle and electric drivetrain controller area network (CAN) busses allow an analysis of the vehicle status in relation to the charging operation on the road. Vehicle speed and position are also recorded. To be able to identify the different losses in the truck, three current probes are mounted around cables for current to the motors, to the auxiliary system, and from the rectifier. This data is collected in a time-synchronized database where it provides a basis for detailed analyses of both individual tests as well as aggregated performance over longer periods.

As an overview of the system a sketch was developed, see Figure 9 .

The part of the system that is examined in this article starts after the transformer and ends before the battery. The losses are primarily resistive; the capacitive and inductive coupling are neglected. The reactive parts of the current will also give losses in the different resistances and will, therefore, be part of the losses. The $R_{\text {Trafo-Rail }}$ is the resistance for the cable going from the transformer to a point at the rail. This includes cables from transformer to contactor cabinet, from cabinet to the rail, approximately $25 \mathrm{~m}$ of the rail. For the eRoadArlanda case, there are 10 cabinets for the $2 \mathrm{~km}$ of electric road in one direction. The resistance in the contactors is neglected. Within the $R_{\text {Trafo-Rail }}$ is also the possible leakage power between the two conductors in the rail, this leakage depends on the contamination of the rail but is constant during the time a vehicle is passing the section. Finally, there are losses in the rectifier that are significant as it is a complex double isolated rectifier unit that can control the charge current delivery to the vehicle.

One loss that is not included in Figure 7 is the heating system for the rail. In cold winters it is necessary to heat the rail to prevent ice build-up in the rail grooves. This could be modeled as a certain power per meter needed. It is only used when the temperature is below freezing. The amount of energy in a year used for this would differ a lot depending on the local climatic conditions where the ERS is to be deployed therefore it will not be included in this article.

To be able to get a value for the total resistance $R_{\text {Trafo-Rail }}$ from after the transformer to a point on the rail, a short circuit test was performed. At the rail, a short circuit tool was applied that shorted the two phases of the rail to the protective ground. Sensors for current and voltage were installed at the output of the transformer after the power breaker. The power breaker was switched on and the sensors were sampled. From this data, the resistance was calculated using Ohm's law:

$$
R_{\text {Trafo-Rail }}=\frac{V_{s}}{I_{s}}
$$

where $V_{s}$ is the voltage peak value recorded during short circuit and $I_{s}$ is the peak current that occurs. This means that the cables and rail are assumed to be purely resistive. 


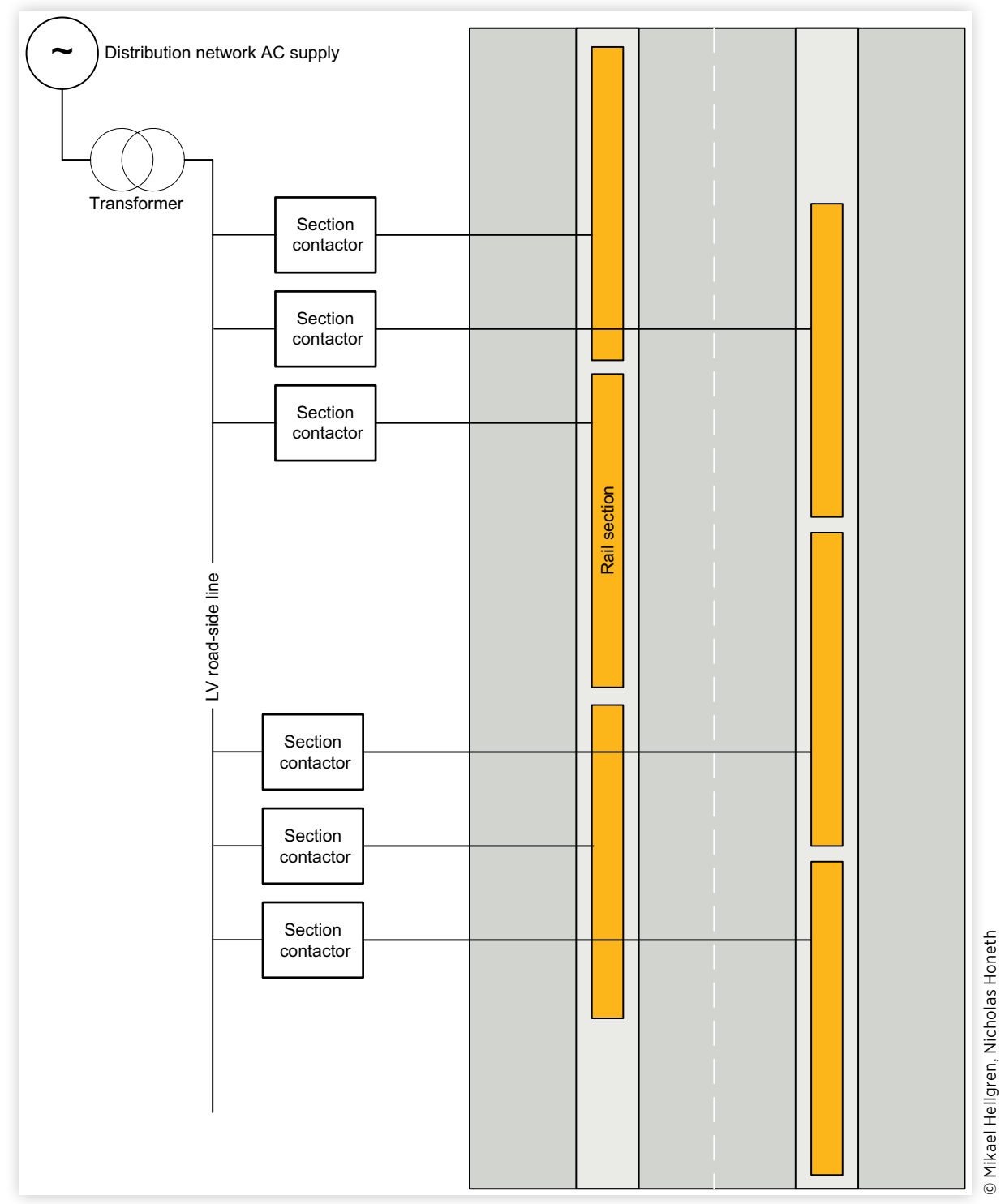

\section{Analysis and Results}

The analysis is presented in three sections, namely, a shortcircuit test used to approximate the line impedance, measurements on the vehicle DC bus, and an analysis of the data collected over the testing period.

\section{Short-Circuit Test}

As described in the previous section a short-circuit test was performed to get the total resistance between the transformer and the rail, this excludes the transformer but includes approximately $25 \mathrm{~m}$ of the rail. The result of the test is shown in Figure 10.

The voltage at short circuit only increases to an $80 \mathrm{~V}$ peak at which the current is approximately $1100 \mathrm{~A}$. In the plot the current has a value of $1180 \mathrm{~A}$ at the same time as the voltage peak, though the mean value of the current has an offset from zero of a little less than $100 \mathrm{~V}$ therefore the value $1100 \mathrm{~A}$ is used. This gives the resistance of $80 / 1100=0.073 \mathrm{Ohm}$ for the $R_{\text {Trafo-Rail }}$. As can be seen in Figure 10, the phase is very close to 0 degrees showing a small inductance in the system. In this article that inductance is not considered.

\section{Rectifier Unit Tests}

What is seen in Figure 11 is from the top downwards power from the roadside supply (dashed) and power into the truck (solid) after the pickup. Both apparent and active power are shown for the supply and vehicle power measurements. The second graph shows the rms current and voltage corresponding to the power measurements. Finally, the third graph 
FIGURE 8 Vehicle data collection system.

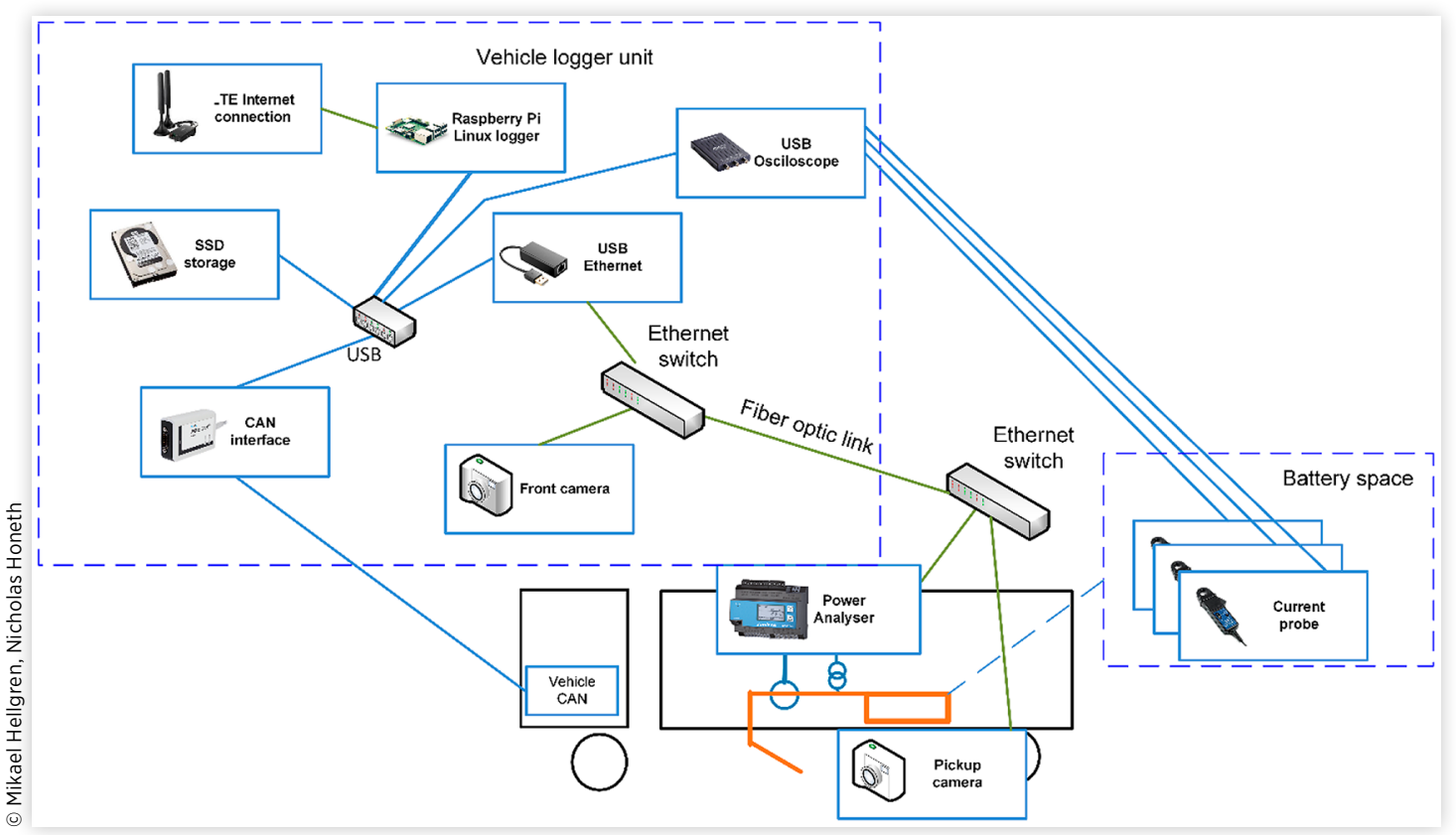

FIGURE 9 Model of the conductive components from the transformer to the battery in the vehicle. Blue dots indicate measurement points.

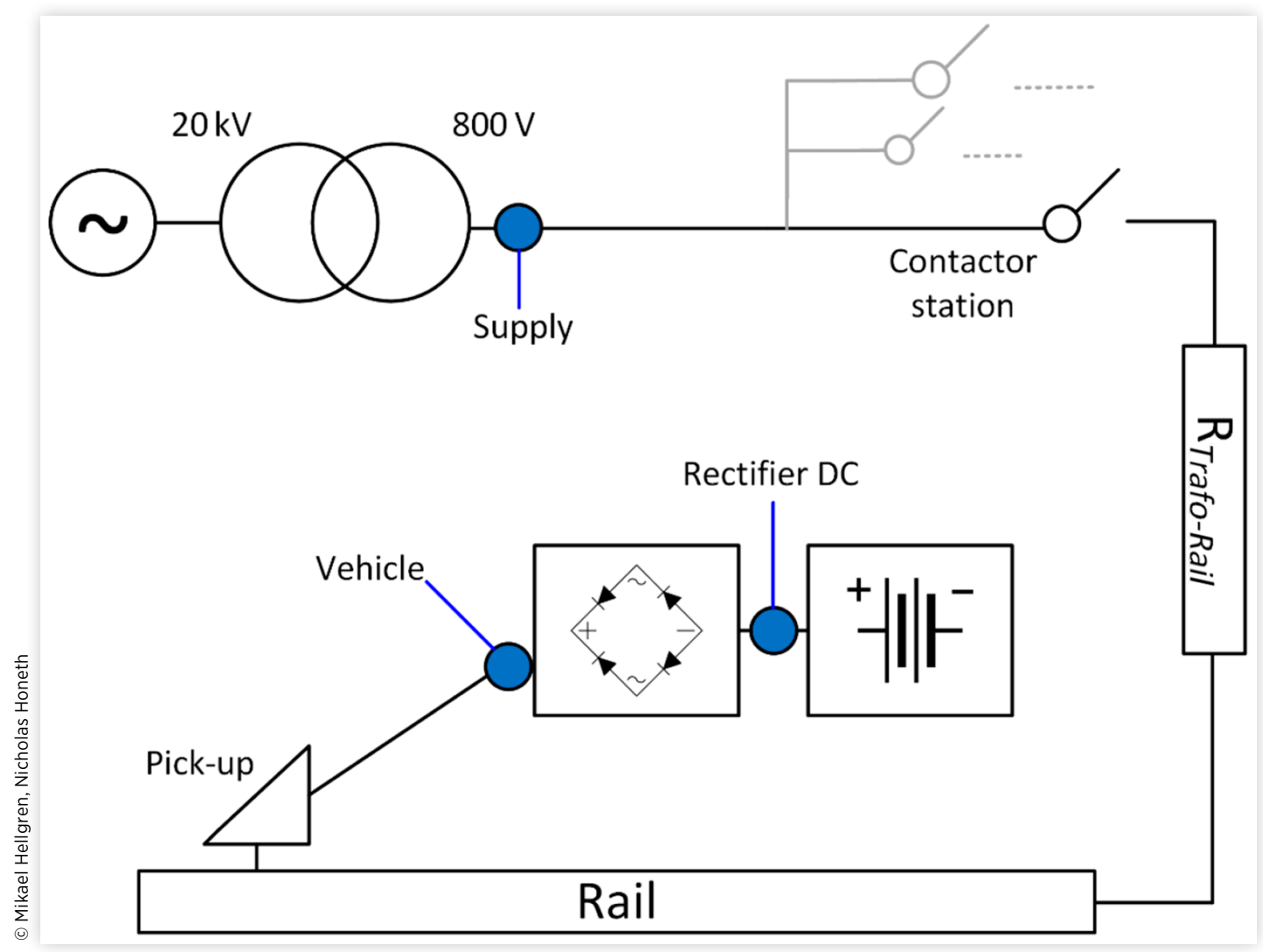


FIGURE 10 Short-circuit test of overcurrent protection.

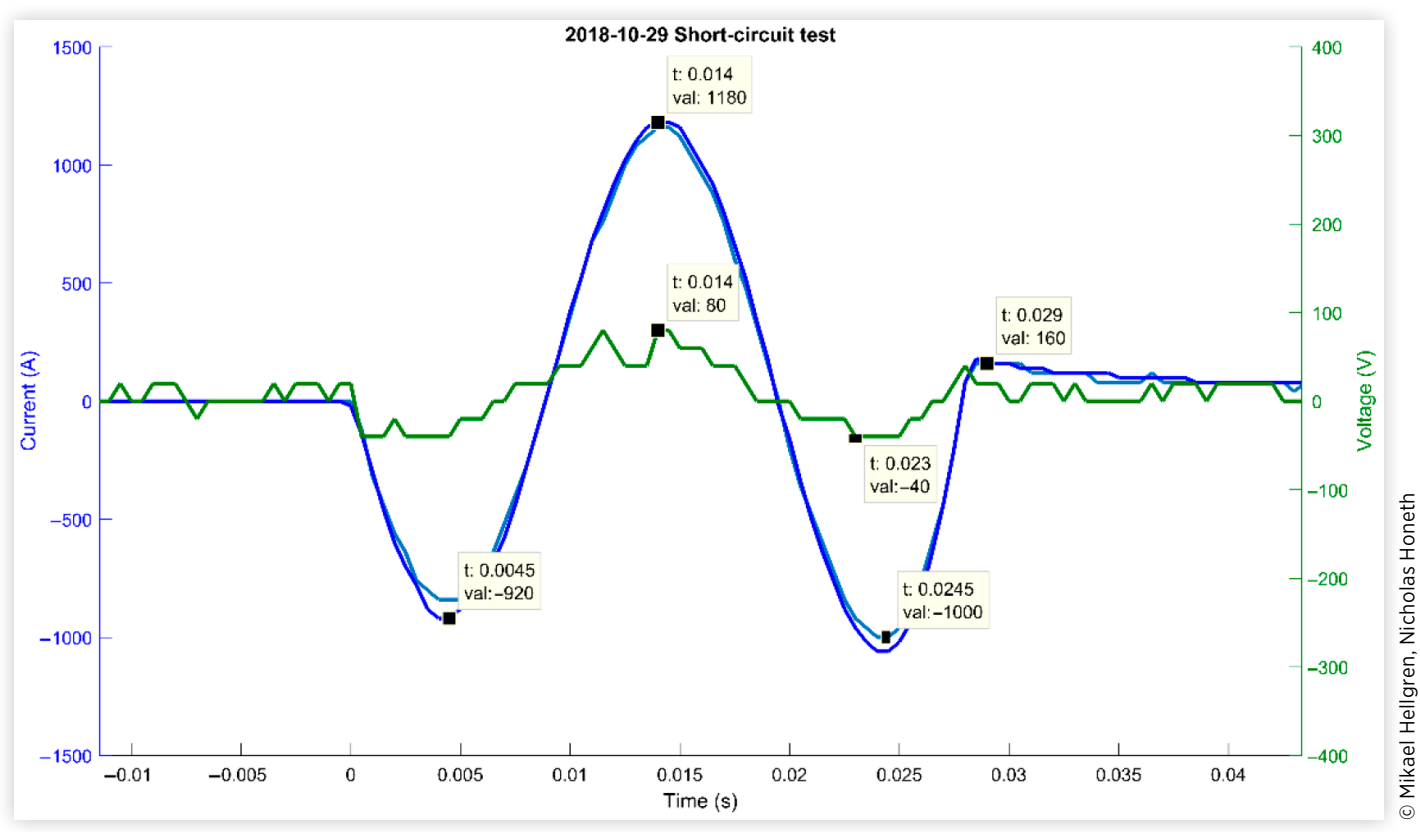

is a plot of the speed of the vehicle, the power in or out of the battery, and the power out of the rectifier. The third graph omits the power to the auxiliary system of the truck. A vehicle system overview and measuring point are given in Figure 12.

The wheels, auxiliary and rectifier currents were measured using current probes, and the "battery in/out" was logged from the drivetrain control system's CAN bus for reference.

The data collected from this system was used to calculate the efficiency of the rectifier system. In Figure 11 graph 1 and 3 , for example, the power out of the rectifier is $60.25 \mathrm{~kW}$ from $73.43 \mathrm{~kW}$ active power measured at the vehicle pick-up. This gives an instantaneous value of $82 \%$. The efficiency of the rectifier unit varies between this value and $89 \%$ depending on the variability of the pick-up connection. The variability of the pick-up voltage is seen in the solid red line in the center plot in Figure 11. Under conditions where the connection between the rail and pick-up is stable, the rectifier unit shows a $7 \%$ performance increase compared to the test shown earlier.

\section{Analysis of Aggregated Data- Losses in System}

In order to expand on the results of the individual tests described earlier, an exploratory analysis of aggregated data from the entire test period is given in this section.

The goal of the analysis is to quantify the end-to-end $\mathrm{AC}$ losses from the supply at the transformer station to the AC measurement point after the pick-up as shown in Figure 8 . The primary variable of interest is the active power loss measured between these measurement points.
The measurement points are selected from data logged continuously during the tests. The selection criteria are based on power measured at both measurement points as well as speed and heading of the test vehicle. The samples from the supply and vehicle are synchronized to a common time reference using the union of the timestamps and linear interpolation between measurements. Outliers from the common timereference set are removed using a Hampel filter. The filtering step removes most of the transients from the set yielding priority to steady-state operation.

The resultant set is visualized in the density plots in Figures 13 and 15 where a particular unit area with higher sample density is darker than unit areas of low sample density.

Figure 13 is marked with areas 1-7 for analysis. The locations of these areas correspond with the charging set points used during the tests and appear at 55, 80,100,120, and $160 \mathrm{~kW}$. The results are deliberately not normalized for the number of tests at each set point in order to preserve the confidence in the sample areas shown. Areas 4 and 7 therefore only include a few tests compared to the higher sample densities in areas 3, 5, and 6 .

A base level of losses of ca. $2 \mathrm{~kW}$ is discernible between areas 1 and 4 , illustrated by a horizontal blue line. This value corresponds to expected losses associated with leakage currents measured during testing. Factors affecting leakage current can include moisture in and around the rail, deicing, mud, gravel, or the insulation materials used in rail construction.

The sample cluster marked in 2 is the result of the peak power draw in the rectifier unit due to the charging of intermediate stage capacitors before beginning to charge the vehicle battery. This occurs as the pick-up first makes contact with the energized rail. Figure 14 exemplifies the rectifier 


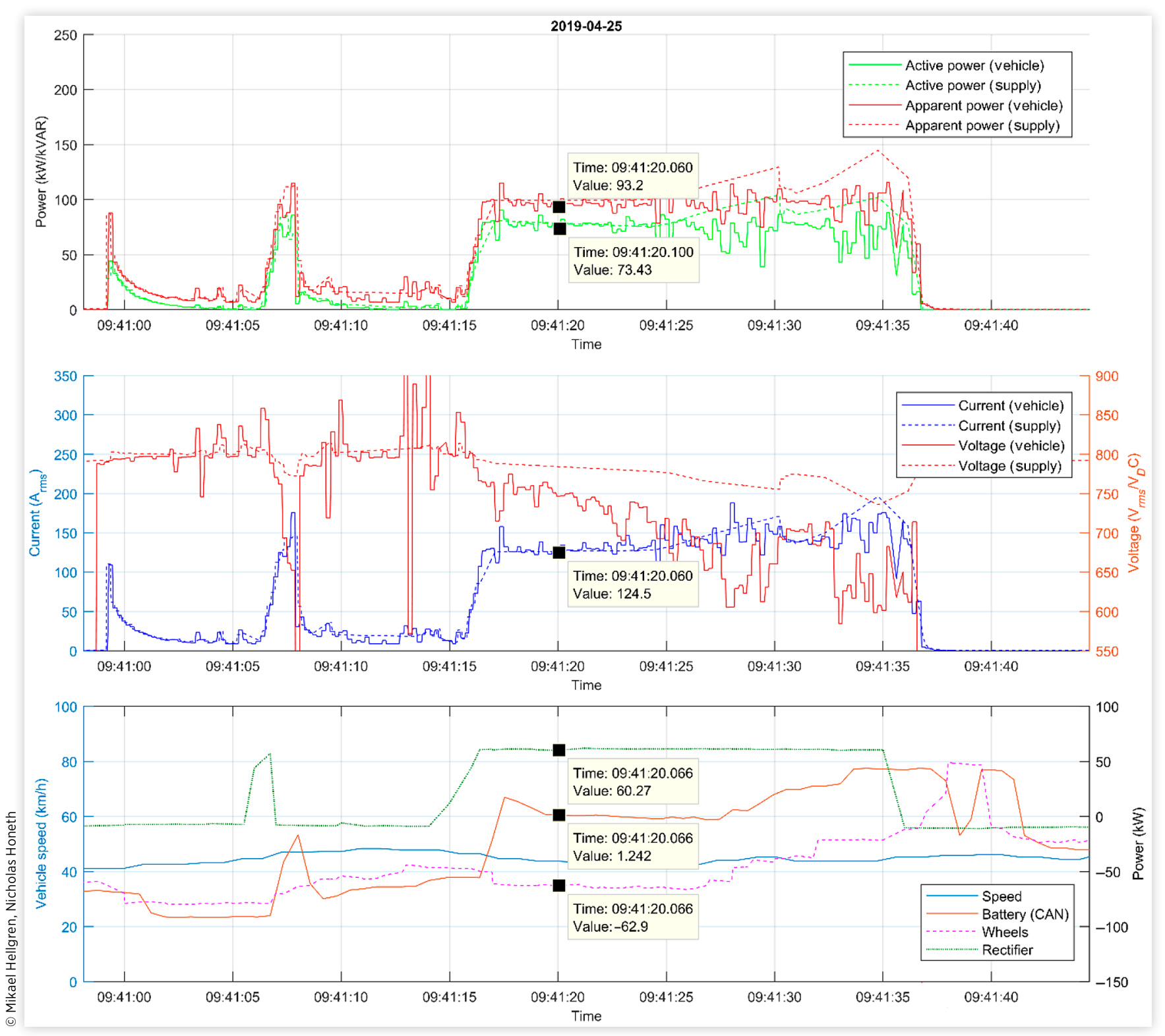

unit capacitor charging. The effect of a large initial inrush current is shown. Within $5 \mathrm{~s}$ of connection the capacitor is charged and after an additional $5 \mathrm{~s}$ delay the rectifier unit ramps up to the charge power set point. This ca. $40 \mathrm{~kW}$ peak is thus overrepresented in the dataset and shows a higher than expected loss for this operational area. Similarly, the wide spread of samples in area 1 reflect the idle state between the capacitor charging phase and when the rectifier unit begins to charge the vehicle battery at the configured power set point. This is also visible in Figure 14 after the initial capacitor charge power and before the battery charge power is ramped-up.

Figure 15 shows the high-power charging measurements in areas 6 and 7 in more detail. While the conductive losses in the feeder cabling begin to dominate over, for instance, the leakage current losses, at these operating power levels the efficiency of the AC conductive transmission to the vehicle shows efficiencies of $92.13 \%$ in area 6 and $92.31 \%$ in area 7 .

Table 2 shows the lowest and highest values of active power efficiency per area with a minimum of 500 samples per unit area. The spread of these values ranges from $83.74 \%$ in area 1 to $96.5 \%$ in area 4 .

These results show how the efficiency in the low power ranges of areas 1 and 2 are low due to leakage currents. At higher charge power set points the cable losses as characterized by the line impedances begin to dominate where the cable dimensioning for the pilot test system achieves the best efficiency at around $80 \mathrm{~kW}$ in area 4 . 


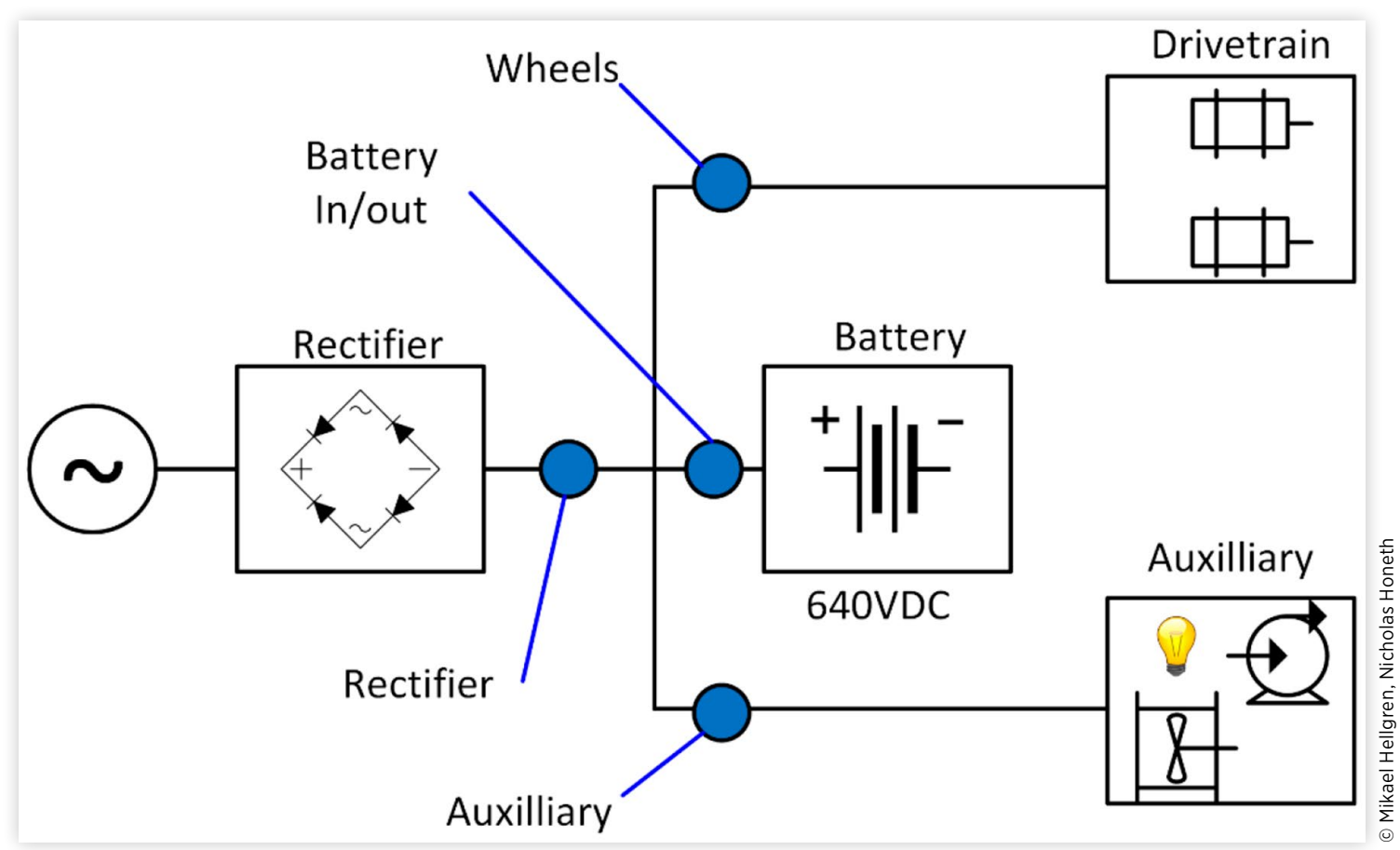

\section{Discussion}

The conductive charging system as used in the eRoadArlanda project reliably demonstrated efficiency in the region of $93-96 \%$ at the charge power of ca. $80 \mathrm{~kW}$ at which point the roadside conductors are appropriately dimensioned.

As explained in the description of the rectifier unit, it is a multistage device providing a galvanic separation required for safe work during the development of the technology. The analysis shows that the efficiency of this unit is comparatively poor especially in the event of unstable pick-up to rail connectivity. This is not to say that the galvanic separation and rectifier stages should be removed, rather that high-efficiency devices that are specifically designed for use with unstable AC supply are required for better performance for vehiclemounted rectifiers. Contemporary power-electronic

\section{FIGURE 13 Sample density plot of active power losses per power measured at pick-up.}

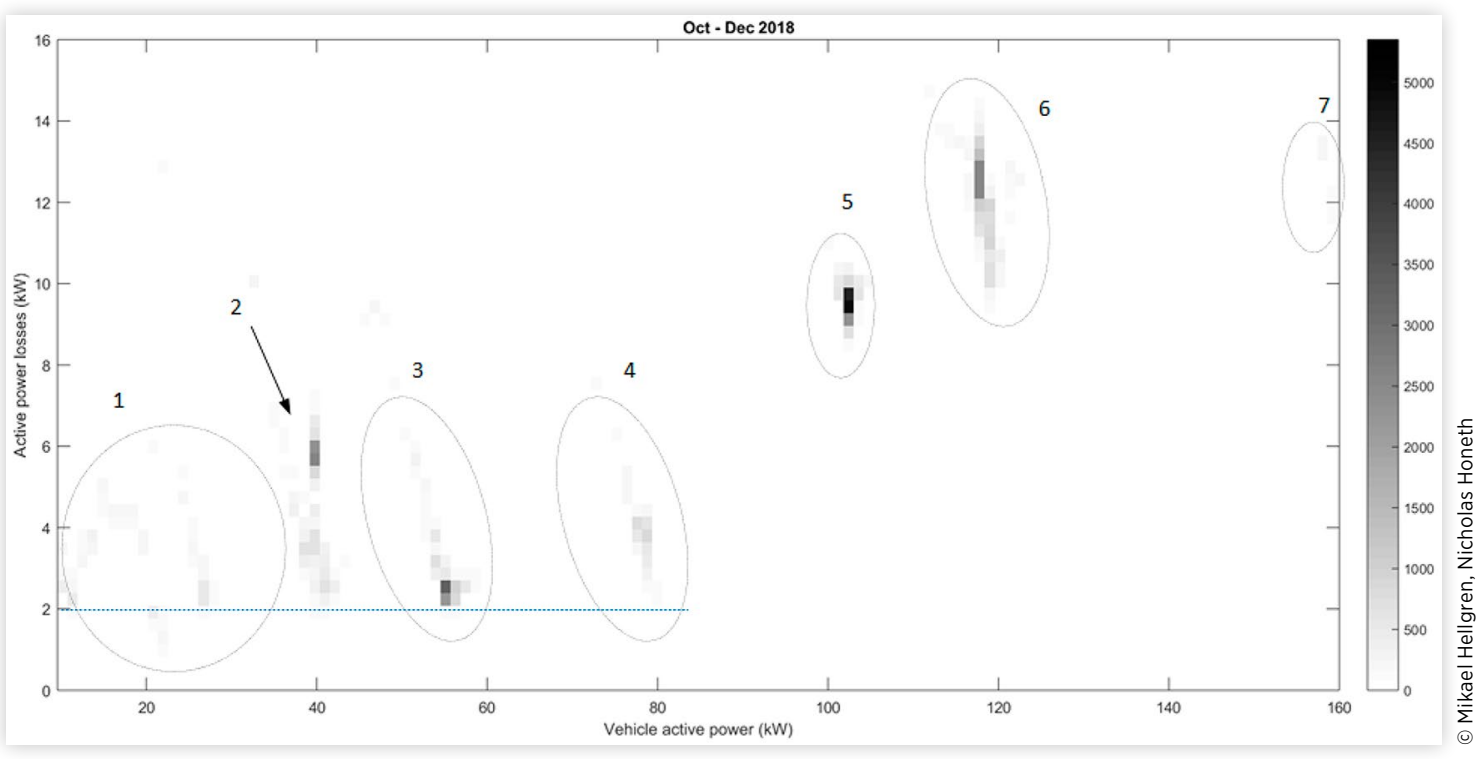


FIGURE 14 Rectifier unit input capacitor charging on pick-up connection.

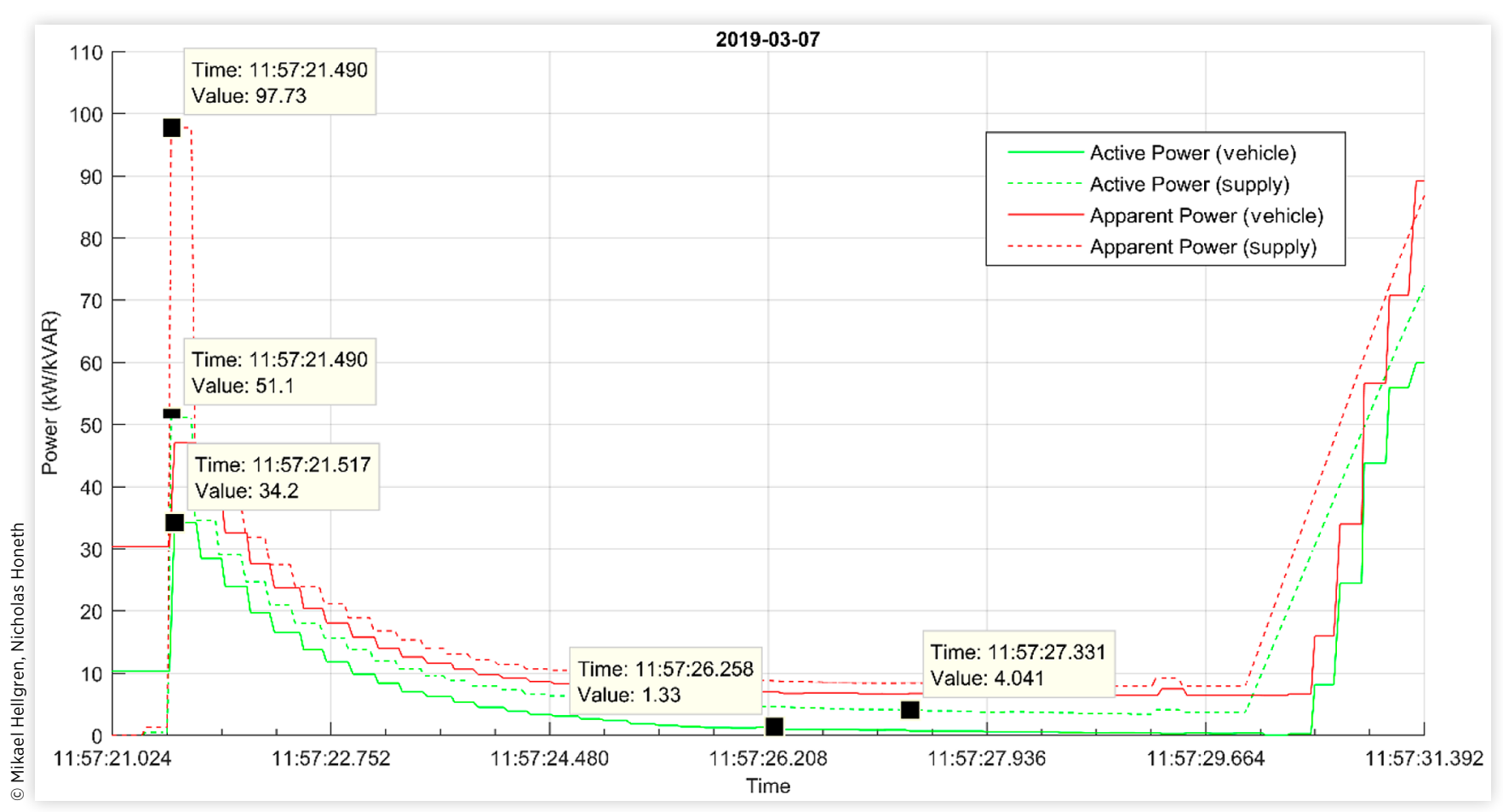

FIGURE 15 Sample density plot of active power losses per power measured at pick-up.

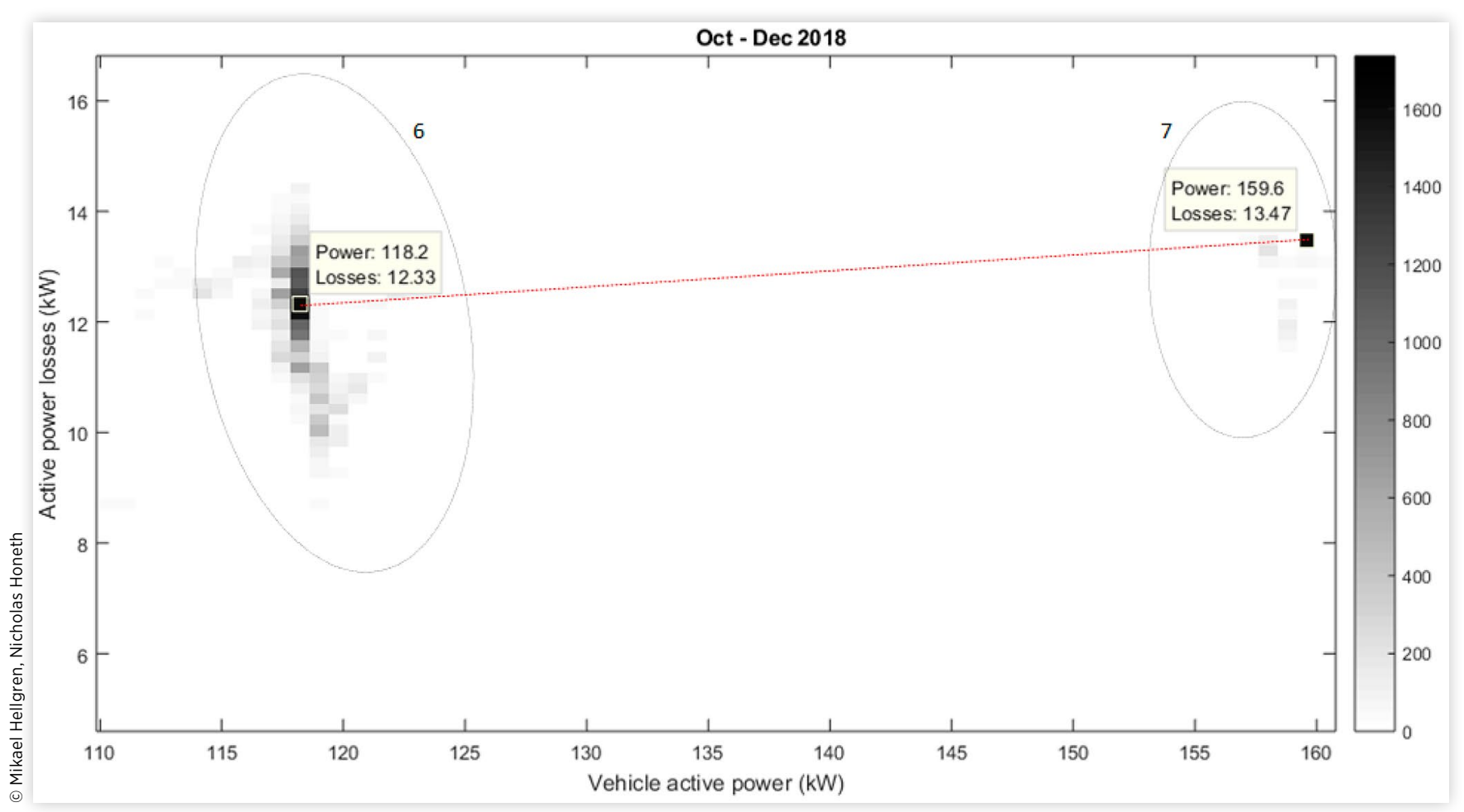


TABLE 2 Sample density plot of active power losses per power measured at pick-up.

\begin{tabular}{|c|c|c|c|}
\hline Area & Active power (kW) & Min efficiency (\%) & Max efficiency (\%) \\
\hline 1 & $<40$ & 83.74 & 92.31 \\
\hline 2 & 40 & 87.52 & 94.98 \\
\hline 3 & 55 & 90.10 & 96.12 \\
\hline 4 & 80 & 93.45 & 96.50 \\
\hline 5 & 100 & 90.81 & 92.09 \\
\hline 6 & 117 & 89.51 & 92.21 \\
\hline 7 & 159 & 92.13 & 92.31 \\
\hline
\end{tabular}

converters are capable of efficiencies of over 96\% [19], meaning that there are considerable performance gains to be had compared to the $82-89 \%$ efficiency measured in the results presented above.

Table 3 lists the efficiencies of the stages in the conductive system contributing to the total end-to-end efficiency for three charge set point levels. The AC conductive efficiencies are calculated from the median values from Table 2 . The rectifier unit efficiency is the median of the values given in the results section. The total end-to-end efficiency is calculated from the product of the AC conductive and rectifier unit efficiencies. Leakage power losses are included in the AC conductive efficiency and are shown for reference.

From the summary in Table 3 it is clear that the multistage rectifier unit used in the eRoadArlanda demonstrator is a major cause of losses in the end-to-end efficiency. The use of high-efficiency rectifier would make end-to-end efficiencies of over $90 \%$ possible.

Conductive charging using alternating current in the rail has certain advantages; equipment such as AC circuit breakers are more readily available at lower cost, and zero-crossing breakers can be used for high-power circuit protection all keep the installation costs down.

However, it may make sense in terms of cost to place the comparatively costly rectifier unit on the roadside as part of the infrastructure rather than in the vehicle as equipment that needs to be owned and maintained by the vehicle operator/ owner. Placing the rectifier at the roadside has the additional benefit of not requiring ride-through capability for unstable AC supply as it would in the vehicle-mounted case.

If the rectifier is instead placed on the roadside near the transformer, supplying DC directly to the vehicles, the maximum power requirement on the rectifier unit will

TABLE 3 Efficiencies in system.

\begin{tabular}{|c|c|c|c|c|}
\hline $\begin{array}{l}\text { Charge set } \\
\text { point (kW) }\end{array}$ & $\begin{array}{l}\text { Leakage } \\
\text { power } \\
\text { losses (\%) }\end{array}$ & $\begin{array}{l}\text { AC } \\
\text { conductive } \\
\text { efficiency } \\
(\%)\end{array}$ & $\begin{array}{l}\text { Rectifier } \\
\text { unit } \\
\text { efficiency } \\
(\%)\end{array}$ & $\begin{array}{l}\text { Total end- } \\
\text { to-end } \\
\text { efficiency } \\
(\%)\end{array}$ \\
\hline 55 & 4 & 93 & 85 & 79 \\
\hline 80 & 3 & 95 & 85 & 81 \\
\hline 100 & 2 & 91.5 & 85 & 78 \\
\hline
\end{tabular}

(c) Mikael Hellgren, Nicholas Honeth be drastically increased. In the case of eRoadArlanda, one transformer feeds $2 \mathrm{~km}$ of electric road. If the distance between each vehicle is $50 \mathrm{~m}$ approximately 40 vehicles could be charged at the same time. With 40 vehicles that take up $200 \mathrm{~kW}$ at the same time, the power requirement would increase to $8 \mathrm{MW}$. This would require a prohibitively large and costly rectifier unit.

In order to address this, a control algorithm for sharing available supply power between vehicles connected to the same supply point could be used. Another solution would be that the rectifier is limited to certain power output and the current could not be increased above a maximum level. The voltage would then fall according to the load. In the vehicle, there must be a function that lowers the power demand if the voltage falls under a certain level. A function like this avoids the requirement for over-dimensioned transformers and rectifiers, which would increase the cost of the installation. The transformer has to be dimensioned equally regardless of whether DC or AC is used for feeding the vehicle.

It is thus essential that installations of conductive in-road charging technology, and arguably alternatives to this technology, are preceded by careful analyses of the expected traffic loads of vehicles utilizing the system for charging and available electric supply infrastructure. These parameters should be used as input for a cost optimization, which considers the total cost of ownership and returns on investment for the infrastructure operator as well as the cost of ownership and incentives for users of the infrastructure, most likely vehicle fleet operators. Considering these factors is important for the adoption and long-term economic viability of the particular installation. Variables that such an optimization can determine thus include the geographical placement and total length of the system, the regularity and rating of transformers connected to the regional power grid, roadside cable dimensions for the low voltage feed from transformer to rail as well as the rectifier power rating.

Findings from this article are applicable to the different conductive systems mentioned in the introduction. For example, dust and salt contamination will present similar challenges for all road-bound solutions. For solutions using the rails from the side of the road, this problem will be less challenging but not totally absent as salty moisture will still be deposited onto the rail in the barrier beside the road. For the overhead conductive system deicing cannot be done with salt instead an electric heat system has to be implemented to have the lines and arms carrying the lines deiced. This means that the cleaning of these solutions is crucial for minimizing the losses in the systems.

\section{Conclusions}

As shown in this article the total efficiency was not as high as it potentially could be. The total efficiency is reduced due to the comparatively low efficiency of the particular rectifier unit used and also due to losses in conductors during high current 
tests. These parts could be enhanced and should be optimized with respect to cost and efficiency.

A conductive system feeding high power will invariably incur conductive losses. At the system design stage, it is therefore important that roadside cabling, power transformer ratings, and the regional grid point of connections are optimized in for cost against expected load from users.

A more fundamental design choice of whether to use the rectifier as part of the roadside infrastructure needs to be addressed. It is reasonable to believe that rectifier will be placed near the transformer in the future instead of in the vehicle, as the rectifier would be both expensive and volume/ weight consuming to have in each vehicle. The less weight that will be carried around in vehicles the better.

As the rectifier unit is a key component the power rating and efficiency needs careful attention at design time. A method for preventing overload of the chosen rectifier should be applied and may require logic or communication to the vehicles.

\section{Contact Information}

\author{
Mikael Hellgren \\ hellgren@kth.se \\ $+46707726306$
}

Nicholas Honeth

honeth@kth.se

$+4687906829$

\section{Acknowledgments}

The authors would like to thank the members of the eRoadArlanda consortium. A specific thank you to the Elways team including Olof Brandt Lundqvist, Morten Svarverud, Henric Dahlström and Gunnar Asplund for facilitating this work during their development. Also, thanks to Hans Johansson associate professor at KTH Mechatronics for ideas of analysis.

\section{References}

1. Al-Thyabat, S., Nakamura, T., Shibata, E., and Iizuka, A., "Adaptation of Minerals Processing Operations for LithiumIon (LiBs) and Nickel Metal Hydride (NiMH) Batteries Recycling: Critical Review," Mineral Engineering 45:417, 2013.

2. Huanga, B., Pana, Z., Sua, X., and Ana, L., "Recycling of Lithium-Ion Batteries: Recent Advances and Perspectives," Journal of Power Source 399:274-286, 2018.

3. Sripad, S. and Viswanathan, V., "Performance Metrics Required of Next-Generation Batteries to Make a Practical Electric Semi Truck," ACS Energy Letters 1669-1673, 2017.
4. “eRoadArlanda Consortium," https://eroadarlanda.com/, accessed June 24, 2019.

5. Orring, A., "Volvos elväg rullar vidare," NyTeknik, June 5, 2013, https://www.nyteknik.se/energi/volvos-elvag-rullarvidare-6403443, accessed June 24, 2019.

6. Zethraeus, D., "First Electric Road in a City," ELONROAD, Apr. 12, 2019, http://elonroad.com/first-electric-road-in-a-city/.

7. Tajima, T., Tanaka, H., Fukuda, T., Nakasato, Y. et al., "Study of High Power Dynamic Charging System," SAE Technical Paper 2017-01-1245, 2017, https://doi.org/10.4271/2017-01$\underline{1245}$.

8. Sandviken Pure Power, "The World's First Electric Highway," https://sandvikenpurepower.se/in-english/electric-highway. html, accessed June 24, 2019.

9. Olsson, O., "Slide-in Electric Road System, Conductive Project Report Created by: Viktoria Swedish ICT on Behalf of Volvo GTT and Scania CV," Volvo GTT, Gothenburg, 2013.

10. Ahn, S., "On-Line Electric Vehicle (OLEV) Project and Vehicular Wireless Power Transfer Technology,” Apr. 6, 2017, http://greentechlatvia.eu/wp-content/uploads/bsk-pdfmanager/2-5a OLEV Project and Technology (Ahn) rev a 15.pdf, accessed June 24, 2019.

11. Goodwin, A., "Qualcomm's Inductive Charging Road Could Pave the Way to New EVs," CNET Road/Show, May 18, 2017, https://www.cnet.com/roadshow/news/qualcommsinductive-charging-road-could-change-the-way-we-buildevs/, accessed June 24, 2019.

12. Morris, C., "Utah State University Builds a Dynamic Wireless Charging Test Track," Charged - Electric Vehicles Magazine, Jan. 7, 2015, https://chargedevs.com/features/ utah-state-university-builds-a-dynamic-wireless-chargingtest-track/, accessed June 7, 2019.

13. Simon, G.B. and Yeshayahou, K., "ElectReon Uses Smart Road Technology for Wireless Charging of Electric Vehicles," Globes - Israel's Business Arena, Feb. 24, 2019, https://en.globes.co.il/en/article-electreon-tel-avivmunicipality-to-lay-pilot-electric-road-1001275432, accessed June 24, 2019.

14. English, C., "Alstom Presents APS for Road, Its Innovative Electric Road Solution," Alstom, Nov. 17, 2017, https://www. alstom.com/press-releases-news/2017/11/alstom-presentsaps-for-road-its-innovative-electric-road-solution, accessed June 24, 2019.

15. Tajima, T., Noguchi, W., and Aruga, T., "Study of a Dynamic Charging System for Achievement of Unlimited Cruising Range in EV," SAE Technical Paper 2015-01-1686, 2015, https://doi.org/10.4271/2015-01-1686.

16. Zavada, J., Zavada, J.B., and Miloš, K., "Conditions for Implementing Trolleybuses in Public Urban Transport," Promet-Traffic \& Transportation 22:467-474, 2010.

17. Tehrani, M.G., Kelkka, J., Sopanen, J., Mikkola, A. et al., "Electric Vehicle Energy Consumption Simulation by Modeling the Efficiency of Driveline Components," SAE Commer. Veh. 9(1):31-39, 2016, https://doi.org/10.4271/201601-9016. 
18. Morozov, A., Humphries, K., Zou, T., Rahman, T. et al., "Design, Analysis, and Optimization of a Multi-Speed Powertrain for Class-7 Electric Trucks," SAE Int. J. Alt. Power. 7(1):27-42, 2018, https://doi.org/10.4271/08-07-01$\underline{0002}$.
19. Mao, S., Wu, T., Lu, X., Popovic, J. et al., "Three-Phase Active Front-End Rectifier Efficiency Improvement with Silicon Carbide Power Semiconductor Devices," in 2016 IEEE Energy Conversion Congress and Exposition (ECCE), Milwaukee, WI, $1-8,2016$.

(c) 2020 Mikael Hellgren, Nicholas Honeth. Published by SAE International. This Open Access article is published under the terms of the Creative Commons Attribution License (http://creativecommons.org/licenses/by/4.0/), which permits distribution, and reproduction in any medium, provided that the original author(s) and the source are credited.

Positions and opinions advanced in this work are those of the author(s) and not necessarily those of SAE International. Responsibility for the content of the work lies solely with the author(s). 